\title{
PENGEMBANGAN LKPD BERBASIS KEARIFAN LOKAL MASYARAKAT PESISIR PANTAI PUGER PADA MATERI PERBANDINGAN
}

\author{
${ }^{1}$ Halimatus Sakdiyah, ${ }^{2}$ Anas Ma'ruf Annizar \\ ${ }^{1,2}$ UIN Kiai Haji Achmad Siddiq Jember, Jl Mataram No.1 Mangli Kaliwates Jember (68136), 0331-487550 \\ e-mail: halimamuhlis99@gmail.com
}

\begin{abstract}
Abstrak
Tujuan dari penelitian ini adalah untuk mengembangkan LKPD berbasis kearifan lokal pada materi perbandingan kelas VII SMP/MTs yang valid, praktis, serta efektif. Metode yang digunakan dalam penelitian ini adalah Research and Development yang mengacu pada model pengembangan ADDIE. Instrumen yang digunakan adalah lembar validasi LKPD, angket respon peserta didik dan guru, serta metode tes (post-test). Berdasarkan hasil uji kevalidan LKPD yang dilakukan oleh validator ahli diperoleh skor rata-rata 92,6\% dengan kategori sangat valid. Kriteria kepraktisan juga terpenuhi, karena LKPD yang dikembangkan mendapatkan ratarata penilaian $83 \%$ untuk angket respon peserta didik, dan $96 \%$ untuk angket respon guru. Sedangkan untuk penilaian keefektifan didapatkan dari penilaian post-test pada saat uji coba, dan data yang diperoleh menunjukkan bahwa sebanyak $86 \%$ peserta didik dikatakan tuntas secara klasikal. Sehingga, LKPD yang dikembangkan dapat dinyatakan valid, praktis dan efektif.
\end{abstract}

Kata Kunci: Kearifan Lokal, LKPD, RnD

\section{Abstract}

This study aims to develop student worksheets based on local wisdom to the material comparison in class VII that is valid, practice, and effective. The method used in this research is Research and Development which refers to the ADDIE development model. The instrument used are LKPD validation sheets and user response quwstionnaries from teachers and students and test method (post-test). Practicality criteria are also met, because the LKPD developed gets an average rating of $83 \%$ for student response questionnaires, and $96 \%$ for teacher response questionnaires. The result of validation conduced by expert validation is $92,6 \%$, so product declared valid. According to the analysis result of the study, the classical troroughness post test is $86 \%$.

Keywords: Local Culture, LKPD, RnD

\section{PENDAHULUAN}

Pendidikan merupakan usaha sebagai sarana pembentukan kemanusiaan, agar kedudukan manusia sebagai subjek dari budaya dapat dipertahankan dan dikembangkan. Sedangkan, pada masa globalisasi seperti saat ini, budaya bangsa sedikit demi sedikit mulai ditinggalkan. Sehingga kesadaran akan budaya harus ditanamkan sejak dini ke dalam jiwa masyarakat Indonesia, salah satu caranya melalui pendidikan. Hubungan pendidikan dengan kebudayaan sangatlah erat, karena semakin tinggi pendidikan seorang maka semakin meningkat kebudayaan yang dimiliki orang tersebut.

Pemerintah telah mengupayakan pelestarian budaya lokal setiap daerah melalui pendidikan. Hal itu terbukti dengan adanya pembelajaran seni budaya, namun distribusi waktu pada pembelajaran tersebut masih kurang sehingga kurang efektif jika ingin menyisipkan unsur budaya pada pembelajaran seni budaya. Salah satu cara yang dinilai lebih 
efektif adalah dengan menyisipkan mata pelajaran yang memiliki waktu kebih panjang, seperti pada mata pelajaran matematika.(Suwito \& Trapsilasiwi, 2016:80)

Pada kurikulum 2013 pemerintah telah menyiapkan bahan ajar berupa buku guru dan buku peserta didik. Namun, materi pada buku tersebut masih bersifat universal. Peserta didik lebih memahami pembelajaran dengan mudah jika materinya dikaitkan dengan lingkungan sekitar. Pengembangan LKPD berbasis kearifan lokal diharapkan menjadi solusi untuk memfasilitasi peserta didik agar mampu memecahkan masalah yang berasal dari masalah sehari-hari. Materi perbandingan dipilih karena peserta didik masih kesulitan untuk mempelajari materi perbandingan terutama pada topik perbandingan berbalik nilai. Dengan adanya LKPD berbasis kearifan lokal peserta didik tidak hanya belajar mengenai materi perbandingan saja, namun juga mempelajari tentang budaya lokal yang ada disekitar.

Indonesia merupakan negara dengan budaya yang beraneka ragam, salah satunya adalah budaya yang ada pada masyarakat di sekitar pesisir pantai Puger. Pantai puger berada di $35 \mathrm{~km}$ arah barat laut kota Jember, yang dikenal sebagai salah satu tempat pelelangan ikan. Selain itu, Puger identik dengan nelayan, karena Puger merupakan basis nelayan di Kabupaten Jember. Dalam kehidupan sehari-hari masyarakat pesisir pantai Puger telah melakukan aktivitas matematika, seperti ketika melakukan jual-beli ikan, membagi hasil tangkapan ikan, pembuatan perahu, serta upacara larung sesaji (petik laut). Akan tetapi, banyak diantara mereka tidak menyadari adanya unsur matematika dalam kegitan tersebut. Sehingga, dengan dikembangkannnya LKPD berbasis budaya lokal peserta didik diharapkan dapat memahami konsep matematika yang dikaitkan dengan budaya masyarakat di sekitar pesisir.

Pengembangan LKPD berbasis kearifan lokal merupakan inovasi untuk membuat kondisi belajar yang menarik agar peserta didik mendapatkan nuansa baru dalam mempelajari matematika. Tujuan dari penelitian ini adalah sebagai berikut :

1. Mendeskripsikan proses pengembangan LKPD berbasis kearifan lokal masyarakat pesisir pantai Puger pada materi perbandingan kelas VII.

2. Mendeskripsikan kelayakan LKPD berbasis kearifan lokal masyarakat pesisir pantai Puger

\section{METODE PENELITIAN}

Model penelitian yang digunakan dalam penelitian ini adalah ADDIE (Analysis, Design, Development, Implementation, and Evaluation). Model ADDIE dipilih karena lebih tepat digunakan untuk mengembangkan LKPD, disusun secara sistematis, dan dalam 
penilaiannya melibatkan penilaian ahli, serta adanya revisi pada setiap tahap sehingga dapat meminimalisir tingkat ketidak validan suatu produk.

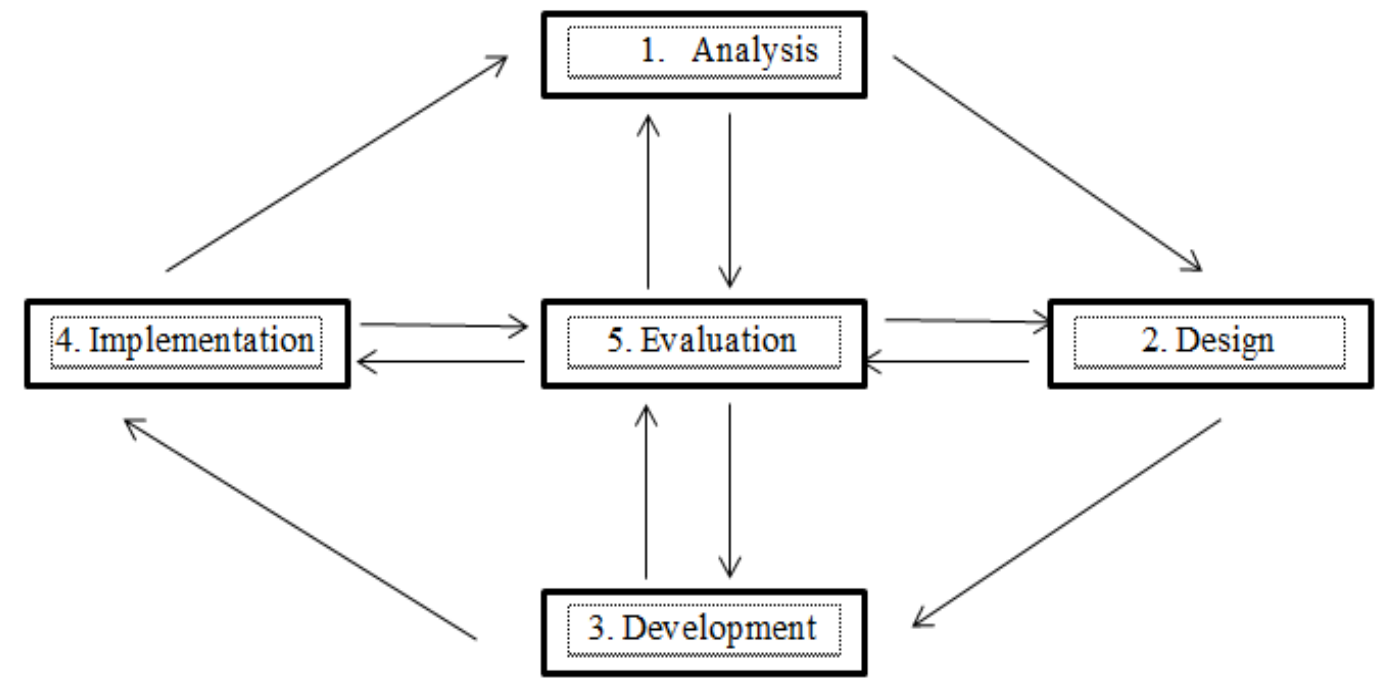

Gambar 1. Model pengembangan ADDIE

Pada tahap analysis terdapat tiga langkah, yaitu: analisis kebutuhan, analisis kondisi peserta didik, serta analisis kearifan lokal. Langkah pertama pada tahap ini adalah menganalisis kebutuhan dengan cara mengidentifikasi masalah pada peserta didik sehingga dapat menentuksn tujuan pengembangan LKPD berbasis kearifan lokal masyarakat pesisir pantai Puger pada materi perbandingan kelas VII.

Pada tahap design terdapat dua langkah, yaitu: desain LKPD dan desain instrument. Tujuan dari tahap desain adalah untuk merancang bentuk awal dari LKPD serta merancang desain instrumen yang akan digunakan untuk menilai produk atau LKPD.

Pada tahap development (pengembangan) terdapat dua langkah, yaitu: pengembangan LKPD serta pengembangan instrument penilaian. Pada pengembangan LKPD kegiatan yang dilakukan peneliti adalah memvalidasi LKPD kepada ahli materi, desain, serta bahasa. Dalam validasi ahli terdapat tiga validator dari dosen tadris Matematika UIN KHAS Jember. Sedangkan pada tahap pengembangan instrument penilaian berfungsi untuk membuat instrumen yang digunakan untuk menilai produk atau LKPD.

Setelah melakukan tahap development, selanjutnya dilakukan tahap implementation (uji coba). Pada tahap uji coba terdapat dua langkah, yaitu: uji coba kelompok kecil dan kelompok besar. Uji coba kelompok kecil dilakukan oleh enam peserta didik yang dipilih secara purposive sampling dan diperoleh respon dari pengguna dalam kegiatan ini guru dan 
peserta didik dimintai responnya terhadap LKPD yang di kembangkan. Kritik serta saran dari pengguna digunakan sebagai perbaikan LKPD sebelum di uji cobakan pada kelompok besar.

1. Instrumen Pengumpulan Data

Penelitian ini menggunakan instrumen penelitian berupa lembar validasi ahli serta angket resepon peserta didik dan guru seta post-test.

2. Teknik Analisis Data

Jenis analisis data yang digunakan dalam penelitian ini adalah analisis deskriptif, yaitu dengan cara menghitung skor rata-rata penilaian tiap indikator validitas LKPD dan rata-rata skor respon pengguna. Kevalidan LKPD yang dikembangkan ditentukan oleh skor yang diberikan oleh tiap ahli sebagai hasil validasi. Kepraktisan LKPD yang dikembangkan diperoleh dari skor respon peserta didik saat uji coba. Sedangkan keefektifan LKPD yang dikembangkan diperoleh dari ketuntasan belajara secara klasikal peserta didik ketika menggunakan LKPD yang dikembangkan.

Tabel 1. Kriteria kevalidan

\begin{tabular}{cl}
\hline Skor & Kriteria \\
\hline $\mathbf{P}>\mathbf{8 1 \%}$ & Sangat Valid \\
$\mathbf{6 1 \%}<\mathbf{P} \leq \mathbf{8 1 \%}$ & Valid \\
$\mathbf{4 1 \%}<\mathbf{P} \leq \mathbf{6 1 \%}$ & Cukup Valid \\
$\mathbf{2 1 \%}<\mathbf{P} \leq \mathbf{4 1 \%}$ & Tidak Valid \\
\hline
\end{tabular}

Rumus yang dipakai untuk penilaian kevalidan yaitu :

$$
P=\frac{f x}{N} \times 100 \%
$$

$$
\begin{aligned}
& \text { Keterangan: } \\
& \begin{array}{l}
\mathrm{P} \quad=\text { Angka presentase angket } \\
f \quad=\text { Jumlah skor yang diperoleh } \\
N \quad=\text { Jumlah Skor maximum }
\end{array}
\end{aligned}
$$

Tabel 2. Skor Penilaian Angket

\begin{tabular}{|c|c|}
\hline Skor & Pilihan Jawaban \\
\hline 4 & Sangat Tinggi \\
\hline 3 & Tinggi \\
\hline 2 & Cukup Tinggi \\
\hline 1 & Rendah \\
\hline
\end{tabular}

Sumber: (Sugiono, 2015)

LKPD dikatakan valid jika pada tiap aspek penilaian memiliki skor minimal 3 dengan kriteria kevalidan $>61 \%$. 
Kepraktisan LKPD dilihat dari respon peserta didik dan guru selaku pengguna LKPD yang dikembangkan dapat disimpulkan bahwa konsep matematika yang berkaitan dengan kearifan lokal masyarakat pesisir, diharapkan dapat menjadi inovasi baru dalam pembelajaran matematika yang menyenangkan. Menurut Saihu (2017) pendidikan berbasis kearifan lokal merupakan sebuah praktek pendidikan yang menghasilkan, menyimpan, menerapkan, dan mewariskan melalui sarana kearifan lokal. Sehingga pengembangan LKPD berbasis kearifan lokal akan membantu menimbulkan rasa cinta peserta didik terhadap budaya.

Tabel 3. Kriteria Kepraktisan

\begin{tabular}{cl}
\hline Skor & Kriteria \\
\hline $\mathbf{P}>\mathbf{8 1 \%}$ & Sangat Praktis \\
$\mathbf{6 1 \%}<\mathbf{P} \leq \mathbf{8 1 \%}$ & Praktis \\
$\mathbf{4 1 \%}<\mathbf{P} \leq \mathbf{6 1 \%}$ & Kurang Praktis \\
$\mathbf{2 1 \%}<\mathbf{P} \leq \mathbf{4 1 \%}$ & Tidak Praktis \\
\hline
\end{tabular}

Keefektifan LKPD dapat dilihat dari presentase minimal ketuntasan belajar peserta didik. LKPD dikatakan efektif jika ketuntasan belajar peserta didik berada pada kategori baik. Ketuntasan belajar peserta didik sesuai dengan KKM yang ditetapkan. Ketentuan ketuntasan belajar klasikal saat post-test dihitung dengan rumus:

$$
p=\frac{\text { banyak siswa yang tuntas }}{\text { banyak siswa dalam satu kelas }} \times 100 \%
$$

Hasil belajar dikatakan tuntas secara klasikal, jika peserta didik yang mencapai KKM $\geq 85 \%$ dari keseluruhan peserta didik yang mengikuti tes.

Subjek Penelitian

\section{HASIL DAN PEMBAHASAN}

Produk yang dihasilkan oleh penelitian ini berupa LKPD yang berbasis kearifan lokal masyarakat pesisir pantai Puger pada materi perbandingan kelas VII. Desain isi LKPD dibuat bernuansa kearifan lokal yang ada di pesisir pantai Puger. 

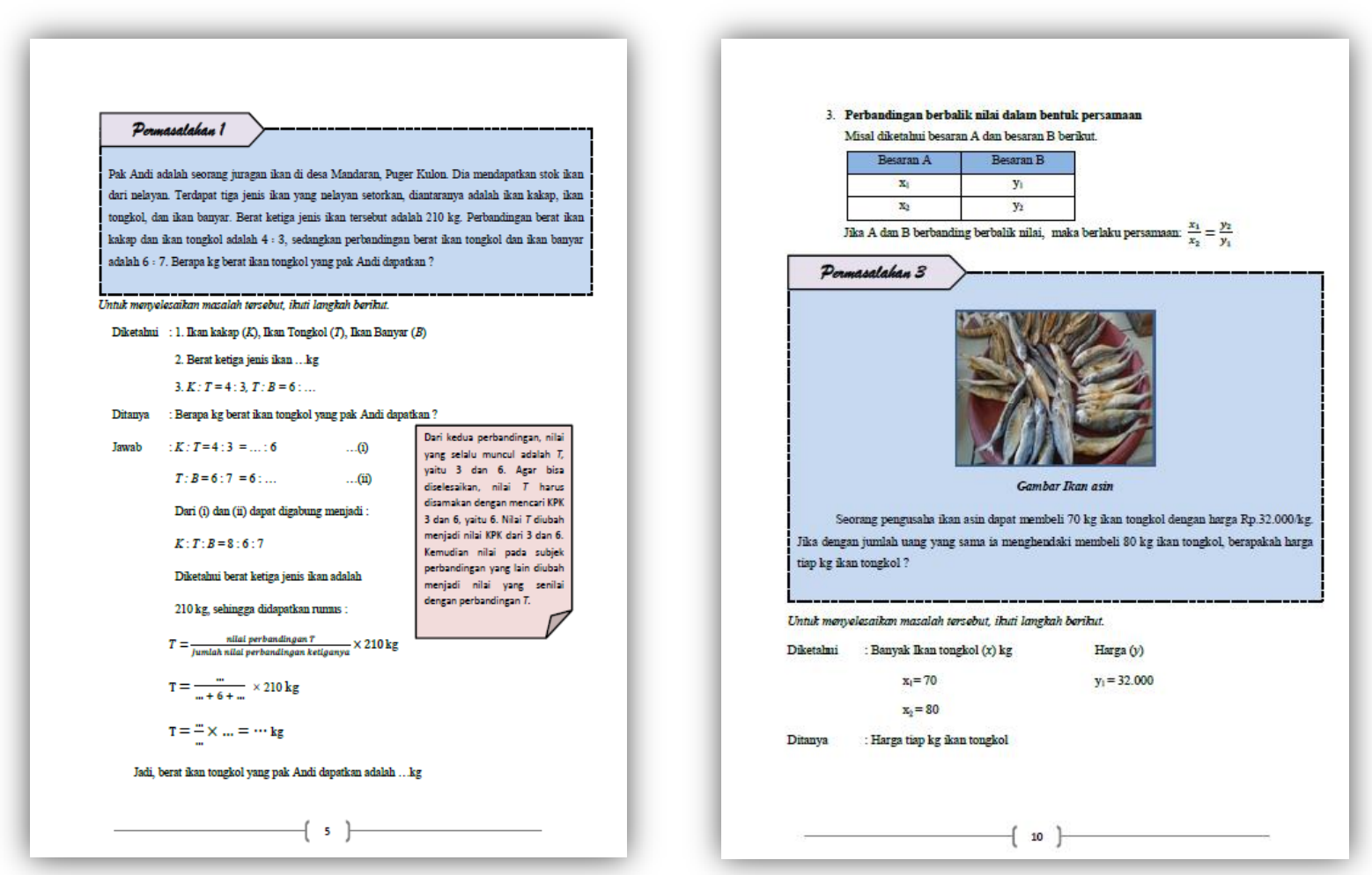

\section{Gambar 2. Contoh LKPD}

Setelah LKPD matematika berbasis kearifan lokal masyarakat pesisir pantai Puger selesai di desain dan dikembangkan, selanjutnya dilakukan uji validasi oleh tiga validator ahli yang ahli materi, ahli bahasa, serta ahli desain. Hasil validasi dapat dilihat pada tabel berikut.

\section{Tabel 4. Data Hasil Analisis Kevalidan}

\begin{tabular}{lcll}
\hline \multicolumn{1}{c|}{ Validator } & Nilai & \multicolumn{1}{c}{ Kriteria } \\
\hline Materi & $100 \%$ & Sangat valid \\
\hline Bahasa & $85 \%$ & Valid \\
\hline Desain & $93 \%$ & Sangat valid \\
\hline Rata-rata & $\mathbf{9 2 , 6 \%}$ & Sangat valid \\
\hline
\end{tabular}

Berdasarkan analisis hasil validasi materi diperoleh presentase sebesar 100\% dengan kategori sangat valid, validasi bahasa diperoleh presentase $85 \%$ dengan kategori sangat valid, serta validasi desain mendapatkan presentase 93\% dengan kategori sangat valid. Dengan demikian skor rata-rata keseluruhan yang didapat adalah 92,6\%. Akbar (2017) mengemukakan bahwa nilai interval $\mathrm{P}>81 \%$ menunjukkan kriteria sangat valid.

Selanjutnya pada kriteria kepraktisan dilakukan uji coba angket respon kepada peserta didik dan guru yang bertujuan untuk mengetahui manfaat serta kemudahan penggunaan LKPD oleh guru maupun peserta didik. Kriteria keprakpraktisan dapat dipenuhi karena ratarata keseluruhan penilaian dari tiap peserta didik dalam kategori sangat baik, dengan 
presentase $83 \%$. Sedangkan skor angket respon guru diperoleh nilai presentase $96 \%$ dengan kategori sangat baik. Dengan demikian LKPD yang dikembangkan dapat dikatakan praktis.

Hasil pengembangan LKPD menunjukkan dapat dikatakan valid serta praktis, namun peneliti melakukan revisi sesuai saran dan masukan yang diberikan oleh masing-masing validator, sehingga dapat menghasilkan LKPD yang sempurna. Adapun hal-hal yang diperbaiki sesuai saran ahli adalah sebagai berikut:

1. Memperbaiki kalimat yang typo atau keliru tata bahasa.

2. Memperbaiki tata letak

3. Memperbaiki kalimat pada soal karena sedikit kurang dipahami.

Tabel 5. Hasil perbaikan sesuai saran ahli

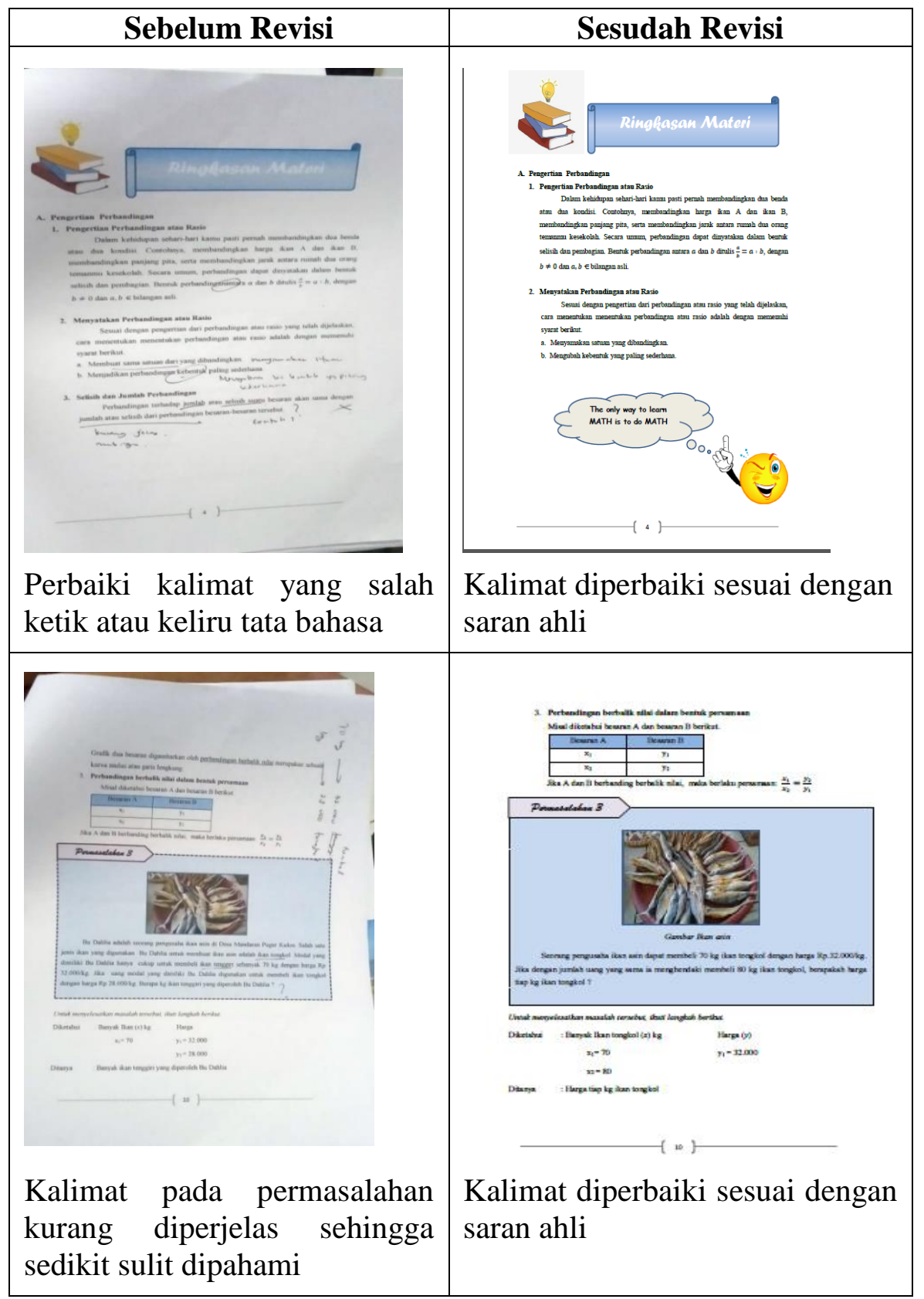




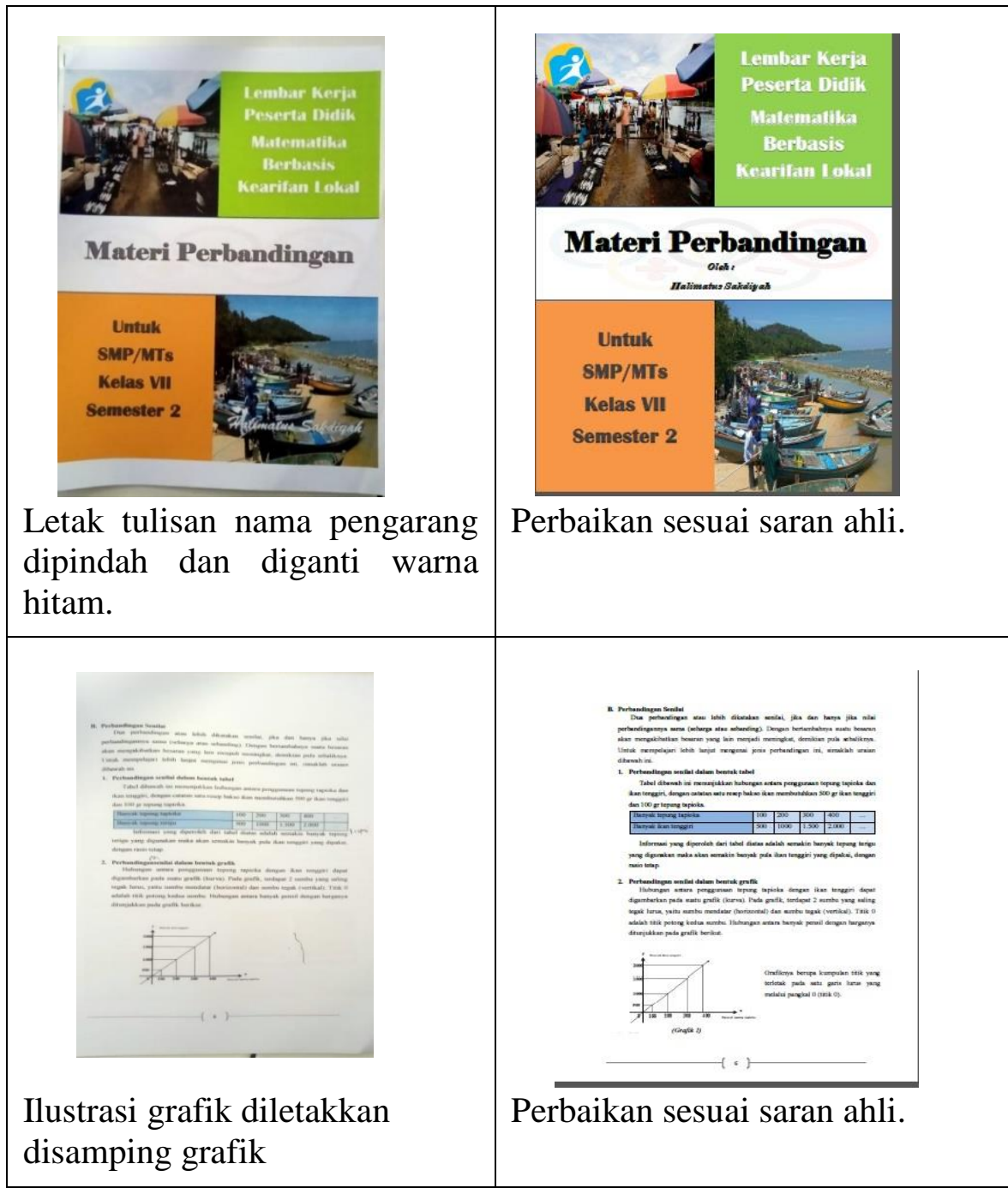

Setelah melakukan uji kepraktisan, selanjutnya uji keefektifan. Pada tahap ini dilakukan uji coba soal post-test terhadap peserta didik kelas VII di MTs. Irsyadun Nasyi'in. Berdasarkan nilai post-test yang diberikan saat uji coba, sebanyak $86 \%$ peserta didik dikatakan tuntas secara klasikal. Hal tersebut sesuai dengan yang dikemukan Mufarizuddin (2017) bahwa hasil belajar dikatakan tuntas secara klasikal jika mencapai 85\% dari jumlah keseluruhan. Dari penjelasan tersebut dapat diketahui bahwa LKPD yang dikembangkan layak untuk digunakan.

Hasil penelitian dan pengembangan ini, menunjukkan bahwa kearifan lokal harus diaplikasikan dalam pembelajaran matematika disekolah. Karena, pembelajaran matematika yang dihubungkan dengan budaya dapat menciptakan pembelajaran yang menarik. Sehingga, dapat menangkap makna secara kontekstual sesuai pengalaman dan pengetahuan awal peserta didik sebagai masyarakat dilingkungannya sendiri. 


\section{KESIMPULAN DAN SARAN}

Berdasarkan hasil analisis data dan pembahasan, maka dapat disimpulkan bahwa

LKPD berbasis kearifan lokal masyarakat pesisir pantai Puger pada materi perbandingan kelas VII dinyatakan valid, praktis, serta efektif.

Penelitian ini diharapkan dapat dikembangkan lebih luas untuk materi lainnya, serta kearifan lokal yang ada pada masyarakat pesisir pantai Puger dapat dieksplorasi lebih mendalam melalui penelitian lanjutan terhadap konsep matematis yang ada pada lingkungan masyarakat pesisir pantai Puger sebagai wilayah kemaritiman.

\section{DAFTAR PUSTAKA}

Akbar, S. 2017. Instrumen Perangkat pembelajaran. Bandung: PT. Remaja Rosdakarya Arikunto, S. 2010. Prosedur Penelitian Suatu Pendekatan Praktik. Jakarta: PT. Rineka Cipta Azizahwati, et.al., Pengembangan Modul Pembelajaran Fisika SMA Berbasis Kearifan Lokal untuk Meningkatkan Hasil Belajar Siswa. Prosiding Pertemuan Ilmiah XXIX HFI Jateng \& DIY, ISSN: 0853-0823 Hal 70-73.

Mufarizuddin. 2017.’Peningkatan Hasil Belajar Matematika Siswa SD Kelas V Melalui Model Pembelajaran Kooperatif Tipe STAD.” Jurnal Pelangi, 9(2), 113-122.

Saputra, A.,Wahyuni, S.,\& Handayani, R. D.(2016). "Pengembangan Modul IPA Berbasis Kearifan Lokal Daerah Pesisir Puger Pada Pokok Bahasan Sistem Transportasi Di SMP.” Jurnal Pembelajaran Fisika, 5(2), 182-188

Saihu, 2019. "Pendidikan Karakter Berbasis Kearifan Lokal (Studi Jembrana Bali).” Edukasi Islami: Jurnal Pendidikan Islam. 8(01), 69-89.

Sugiyono, 2010. Metodologi Penelitian Pendidikan. Bandung: Alfabeta.

Suwito, A., \& Trapsilasiwi, D. (2016).“Pengembangan Model Pembelajaran Matematika SMP Kelas VII Berbasis Kehidupan Masyarakat JAWARA (Jawa dan Madura) Di Kabupaten Jember.” Jurnal Ilmiah Pendidikan Matematika 4(2), 80. 